\title{
SISTEM PENAMPIL INFORMASI KOLEKSI BATIK BERBASIS QR CODE DI GEDUNG SEMINAR SITI WALIDAH MUHAMMADIYAH SURAKARTA
}

\author{
Eri Prawira Kadarisman ${ }^{1)}$, Heru Supriyono ${ }^{2)}$ \\ ${ }^{1,2)}$ Program Studi Informatika, Universitas Muhammadiyah Surakarta \\ 1) erikadarisman@gmail.com, ${ }^{2)}$ heru.supriyono@ums.ac.id
}

\begin{abstract}
The seminar room of Siti Walidah building is often visited by students or general public in which there are ancient batik collection displayed on its wall without any information about them. Smartphone technology has grown rapidly in which people can obtain information needed very easily. QR Code is an easy method to get complete information. QR Code is a type of image that stores data in the form of a barcode matrix in it. The purpose of this research is to make visitor $s$ get information about the displayed batik by using their smartphone. The method used in this study was the System Development Life Cycle (SDLC). The results obtained from this research were that the website admin systems managed batik information and the android application serves as information viewers of the batik collections that utilize the QR Code to be scanned. The testing carried out by the writer provided users with a comfortable experience to use the system and check whether it had worked correctly according to its function. The testing was done by testing the blackbox that made the results run well. In testing the $Q R$ Code, the application scanned the image with sufficient lighting on ideal distance of $20 \mathrm{~cm}$ to $40 \mathrm{~cm}$. On QR scribble tests, the code in the fifth streak could not be scanned. For testing, smartphones with various specifications successfully ran the application and in testing the questionnaire, it produced an average accuracy of $88 \%$. It is finally concluded that the application can help visitors to find out information about the batik displayed on the wall of the seminar room of Siti Walidah building, Muhammadiyah University of Surakarta.
\end{abstract}

Keywords: Smartphone, Website, QR Code, Android.

\section{PENDAHULUAN}

Gedung Siti Walidah merupakan Gedung rektorat Universitas Muhammadiyah Surakarta, Gedung yang terletak di jalan Ahmad Yani, Pabelan, Kartasura. Gedung ini merupakan kantor pusat terpadu yang berfungsi sebagai kantor rektorat, kantor pusat biro dan unit pelayanan kepada mahasiswa, kantor urusan internasional dan sebagai kantor admisi yang berfungsi sebagai berikut sebagai pusat pelayanan penerimaan mahasiswa baru. Gedung Siti Walidah mempunyai ruang seminar yang berada di lantai 7, didalamnya terdapat \pm 100 koleksi batik kuno sebagai dekorasi ruang.

Berdasarkan pengamatan yang saya lakukan bahwa pengunjung tidak mengetahui detail tentang koleksi batik tersebut. Koleksi batik tidak mempunyai nama dan tidak ada deskripsi yang lengkap. Dari permasalahan tersebut penelitian ini memilki alternatif untuk membuat sistem informasi dan aplikasi android dapat diakses secara menyeluruh dengan informasi lengkap melalui smartphone.

Menurut (Pandya \& Galiyawala, 2014) QR Code adalah merek dagang untuk jenis barcode matrix yang ditemukan oleh perusahaan Jepang Denso Wave. $Q R$ Code merupakan singkatan dari Quick Response Code yang dapat dibaca mesin, matriks barcode dimana data dimasukkan didalam arah vertikal dan horizontal (Pal \& Jha, 2017). Kapasitas penyimpanan kode QR hingga 4.296 karakter alfanumerik dari data atau kode yang dimasukkan agar bisa dibaca dengan aplikasi pemindai android (Nugroho \& Efendi, 2018). 
Menurut penelitian yang dilakukan oleh (Shamal, Monika, \& Neha, 2014) mengembangkan aplikasi android berbasis teknologi cloud computing dan QR Code bertujuan untuk mempermudah petugas Kemenhub dalam melakukan perekapan dan pengolahan data bus dan penumpang yang keluar masuk terminal. Manfaat dari $Q R$ Code ini memudahkan pengguna smartphone mengakses informasi dan membuat $Q R$ Code dengan bebas dan mudah.

Pada penelitian yang dilakukan oleh (Ugwu \& Mesigo, 2015) menjelaskan android ialah aplikasi didasarkan bahasa Java karena itu memungkinkan pengembangan untuk dalam Bahasa Java oleh karena itu dapat mengontrol smartphone melalui Google-enabled Java libraries sistem ini dikembangkan menggunakan Android Studio. Pada penelitian selanjutnya yang dilakukan oleh (Raj, Subramanian, \& Rupasudha, 2017) menyampaikan alasan memilih android yaitu android merupakan sistem operasi seluler berdasarkan Kernel Linux, yang rancang untuk smartphone. Sistem operasi ini memiliki basis terbesar yang dipakai sejak 2013 android merupakan sistem operasi terlaris.

Berdasakan uraian permasalahan tersebut, maka penelitian ini dilakukan dengan tujuan untuk memudahkan pengunjung mendapatkan informasi dengan membuat sistem informasi koleksi batik dengan menggunakan web dan aplikasi android. Dengan web admin dapat mengelola informasi koleksi batik yang ada, sedangkan aplikasi android dibuat untuk menampilkan informasi ke pengunjung dengan memanfaatkan smartphone android yang dirancang untuk memenuhi kebutuhan informasi penampil koleksi batik menggunakan $Q R$ Code

\section{TINJAUAN PUSTAKA}

Penelitian terdahulu yang telah dilakukan oleh (Adrianto et al., 2015) yaitu aplikasi Xserve yang berguna untuk memesan makanan dengan memindai $Q R$ Code yang disediakan untuk identifikasi nomor meja. Sistem ini dapat melihat dan melakukan pemasanan dengan tidak harus terhubung internet karena menggunakan jaringan hot-spot restoran.

Perbedaan dengan aplikasi yang pernah ada dengan Sistem Penampil Batik adalah pada bagian backend menggunakan web dan menggunakan layanan hosting agar lebih mudah dalam mengelola informasi. Konsep dalam Sistem Penampil Batik adalah untuk memudahkan pengguna dalam mendapat informasi batik dan memudahkan admin untuk mengelola informasi. Perbedaan lainnya adalah pada pemindaian $Q R$ Code yang berfungsi sebagai identifikasi batik.

\section{METODE PENELITIAN}

Dalam penelitian ini, menggunakan metode untuk membangun sistem penampil informasi koleksi batik berbasis $Q R$ Code yaitu model System Development Cycle (SDLC) dengan pendekatan model Waterfall.

\subsection{Analisis Kebutuhan}

Pada langkah ini, diperlukan alat untuk membuat sistem penampil informasi koleksi batik berbasis $Q R$ Code, baik kebutuhan hardware maupun software, seperti pada Tabel 1. 
Tabel 1. Kebutuhan hardware maupun software

\begin{tabular}{|c|c|}
\hline Hardware & Software \\
\hline $\begin{array}{ll}\text { a. } & \text { Asus A4451 } \\
\text { b. } & \text { Asus Zenfone } 3\end{array}$ & $\begin{array}{ll}\text { a. } & \text { Visual Studio Code } \\
\text { b. } & \text { Android Studio } \\
\text { c. Xampp Control Panel } \\
\text { d. } & \text { Google Chrome } \\
\text { e. } & \text { Corel Draw X7 }\end{array}$ \\
\hline
\end{tabular}

\subsection{Pengumpulan Data}

Dalam melakukan pengumpulan data, meliputi informasi tempat ruang seminar, foto koleksi di dalam ruang seminar, identitas koleksi batik di ruang seminar, dan mencari referensi dari berbagai sumber seperti jurnal, skripsi, situs internet dan buku yang berkaitan dengan pembuatan sistem. Penulis juga menyiapkan web dan aplikasi android, dari data yang telah dikumpulkan dengan tujuan mempermudah penelitian dan pengujian sistem yang akan dibuat.

\subsection{Perancangan Sistem Aplikasi}

Sistem ini menggunakan website dengan bahasa pemrograman PHP dan aplikasi android dengan android studio. Dalam perancangan akan menjelaskan tentang alur kerja system, relasi table, hak akses yang dimiliki admin dan pengguna ketika sistem informasi dia jalankan. Hak akses penuh kepada admin untuk mengelola informasi yang ditampilkan. Didalam halaman admin memiliki fitur sebagai berikut: menambah, mengedit dan menghapus informasi koleksi batik, serta dihalaman admin terdapat $Q R$ Code generator yang nantinya akan dipindai menggunakan aplikasi android. Didalam $Q R$ Code akan berisi berupa code unik yang berfungsi untuk penampil koleksi batik berbasis aplikasi android. Dengan cara ini pengunjung hanya memerlukan aplikasi android yang akan dibuat agar informasi pada koleksi batik dapat disampaikan secara lengkap dan efisien.

Dengan aplikasi android yang akan dibuat agar user bisa memindai $Q R$ Code sedangkan admin mendapatkan hak penuh mengelola informasi yang terdapat pada sistem informasi pada web. Untuk memperjelas keterangan diatas dapat ditambahkan diagram use case. Diagram akan menjelaskan gambaran interaksi yang terjadi antara actor dengan setiap fungsi pada sebuah sistem. Usecase diagram di penelitian ini di gambarkan pada Gambar 1

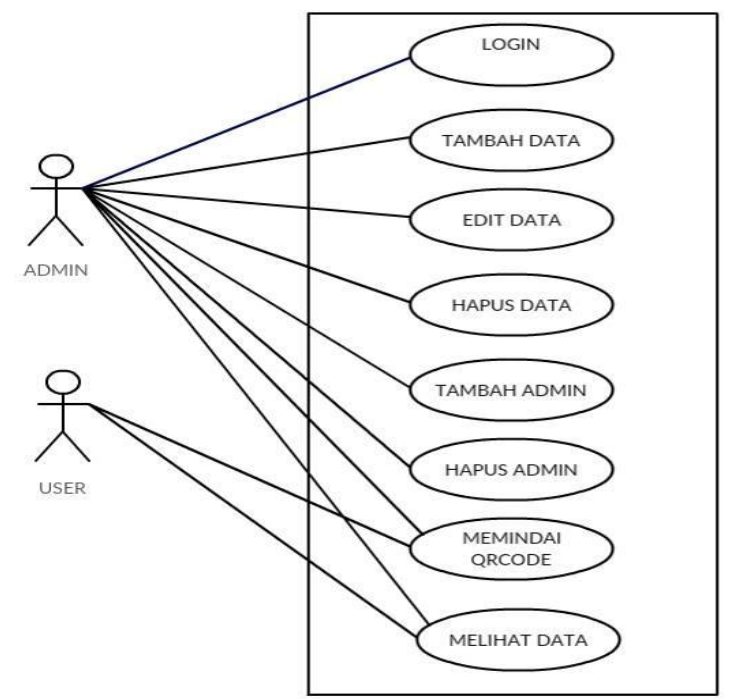

Gambar 1. Use case diagram admin dan user 
Didalam tabel relasi menjelaskan tentang alur pola database dan perubahan data informasi koleksi. Didalam database terdapat 2 tabel, table pertama bernama admin yang menyimpan data admin, table kedua bernama koleksi yang menyimpan data koleksi batik. Selebihnya dapat dilihat pada Gambar 2.
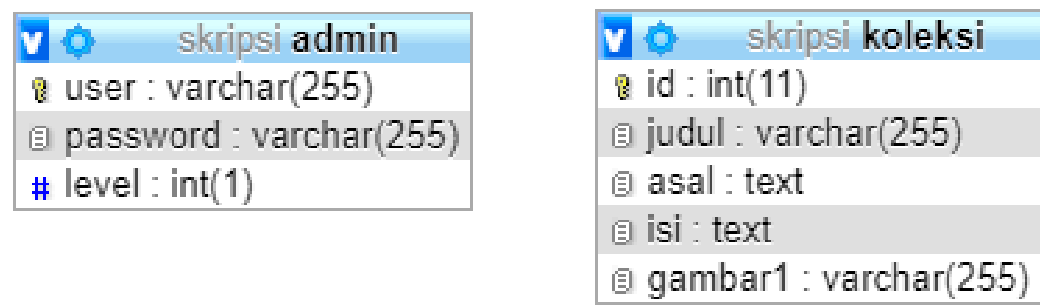

Gambar 2. Diagram database admin dan koleksi

\section{Gambar Flowchart konsep Aplikasi $Q R$ Code}

Pada Flowchart akan menjelaskan proses aktivitas yang dilakukan sistem aplikasi ini dilihat pada Gambar 3 yang dimulai dari menu pada aplikasi android sampai proses pindai dengan aplikasi dan kemudian muncul informasi yang dipindai dari aplikasi android. Proses pertama user akan memilih menu yang berisikan scan dan about. Selanjutnya, user dapat memilih scan untuk memindai $Q R$ Code yang ada. Setelah dipindai maka aplikasi akan menampilkan informasi sesuai dengan $Q R$ Code.

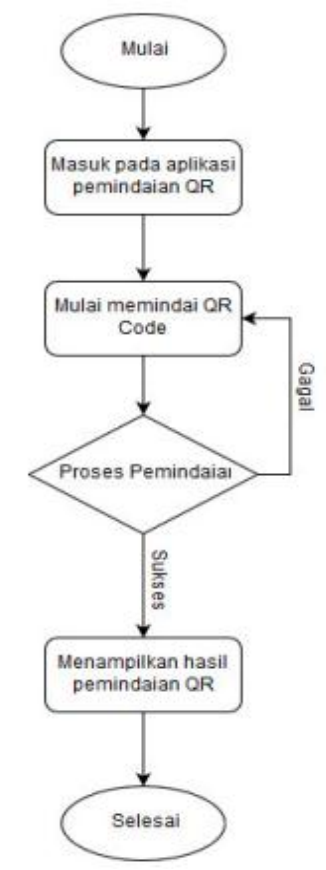

Gambar 3. Flowchart aplikasi QR Code

\section{Alur Kerja Sistem $Q R$ Code}

Alur kerja dari sistem $Q R$ Code hanya dengan memanfaatkan smartphone yang kemudian menginstal aplikasi yang telah dibuat dalam penelitian ini dengan memanfaatkan kamera smartphone untuk memindai $Q R$ Code. Dapat dilihat pada Gambar 4. 


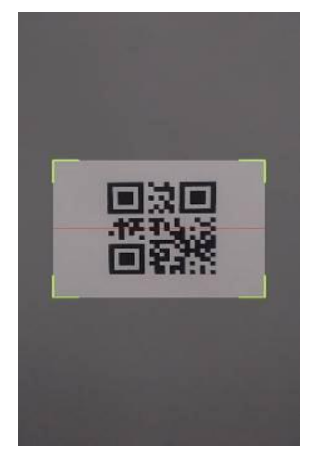

Pemindai $Q R$ Code

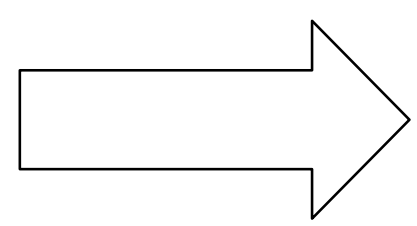

Gambar 4. Alur kerja sistem $Q R$ Code

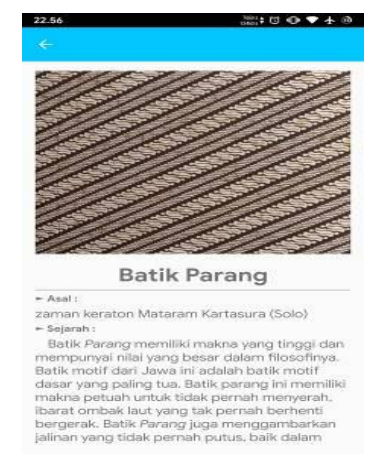

Hasil

\subsection{Perancangan Tampilan Aplikasi}

Pada tahap ini akan menampilkan rancangan tampilan web yang diperuntukan untuk admin dan versi aplikasi android untuk user. Rancangan ini juga sebagai acuan dalam pembuatan web dan aplikasi android. Untuk versi web admin dapat dilihat Gambar 5

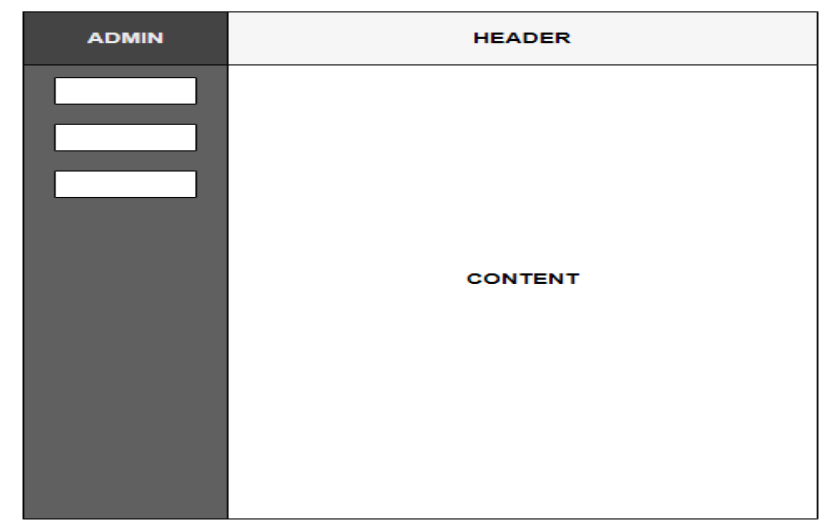

Gambar 5. Rancangan web untuk admin

Untuk aplikasi android, tampilan akan ada menu, pemindai $Q R$ Code, dan penampil content yang akan menampilkan informasi koleksi batik setelah memindai $Q R$ Code. Untuk versi android pada user dapat dilihat Gambar 6.
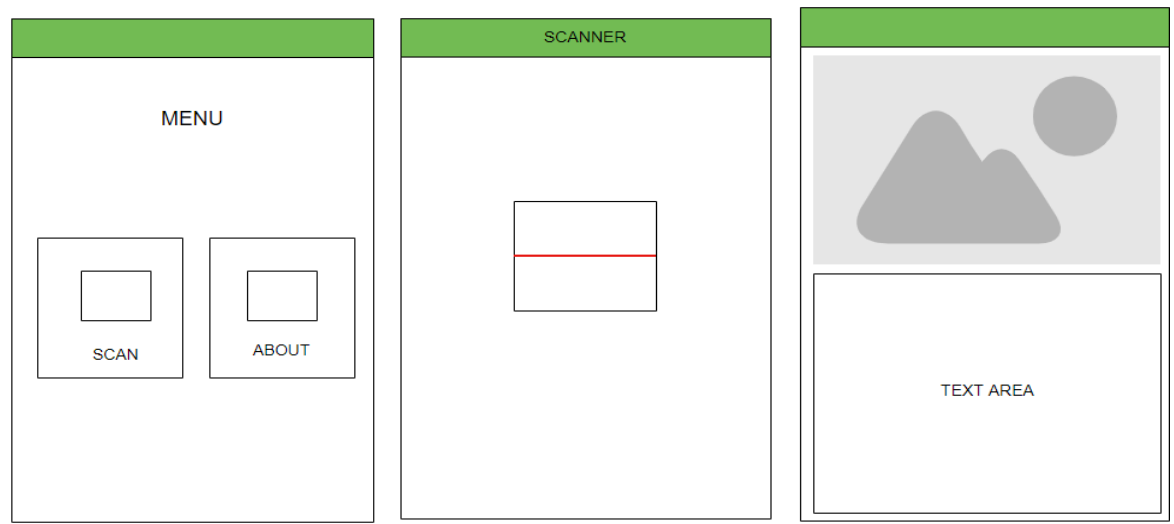

Gambar 6. Rancangan aplikasi untuk user 


\subsection{Pengujian}

Setelah web dan aplikasi pengujian akan fungsi-fungsi pada sistem sudah sesuai dengan yang direncanakan dan pengujian $Q R$ Code dilakukan simulasi untuk melihat sistem berjalan dengan baik di beberapa kondisi.

\subsection{Implementasi}

Tahap terakhir adalah pengimplementasian sistem informasi web dan aplikasi android koleksi batik berbasis $Q R$ Code, yang diimplementasikan di ruang seminar Gedung Siti Walidah untuk membantu menyampaikan informasi dari koleksi batik dan untuk mengelola data koleksi batik.

\section{HASIL DAN PEMBAHASAN}

Hasil yang dicapai pada penelitian ini terdapat 2 bagian, yaitu hasil desain web dan Aplikasi android QR Code.

\subsection{Hasil Tampilan Sistem Admin}

Tampilan web ini berperan mengelola informasi dengan fitur seperti, menambahkan koleksi, mengupdate data, dan menghapus data. Untuk mengakses web admin diperlukan Login dengan memasukkan username dan password. Fitur lainnya juga terdapat pada halaman yang berisi tabel yang berisi koleksi yang sudah ditambahkan oleh admin, dan hanya super admin yang bisa menambahkan admin baru untuk membantu mengelola informasi

\section{Tampilan Login Web Admin}

Login di gunakan untuk mengamankan web admin karena hanya admin yang berhak mengelola informasi pada sistem informasi koleksi batik. Dapat dilihat pada Gambar 7.

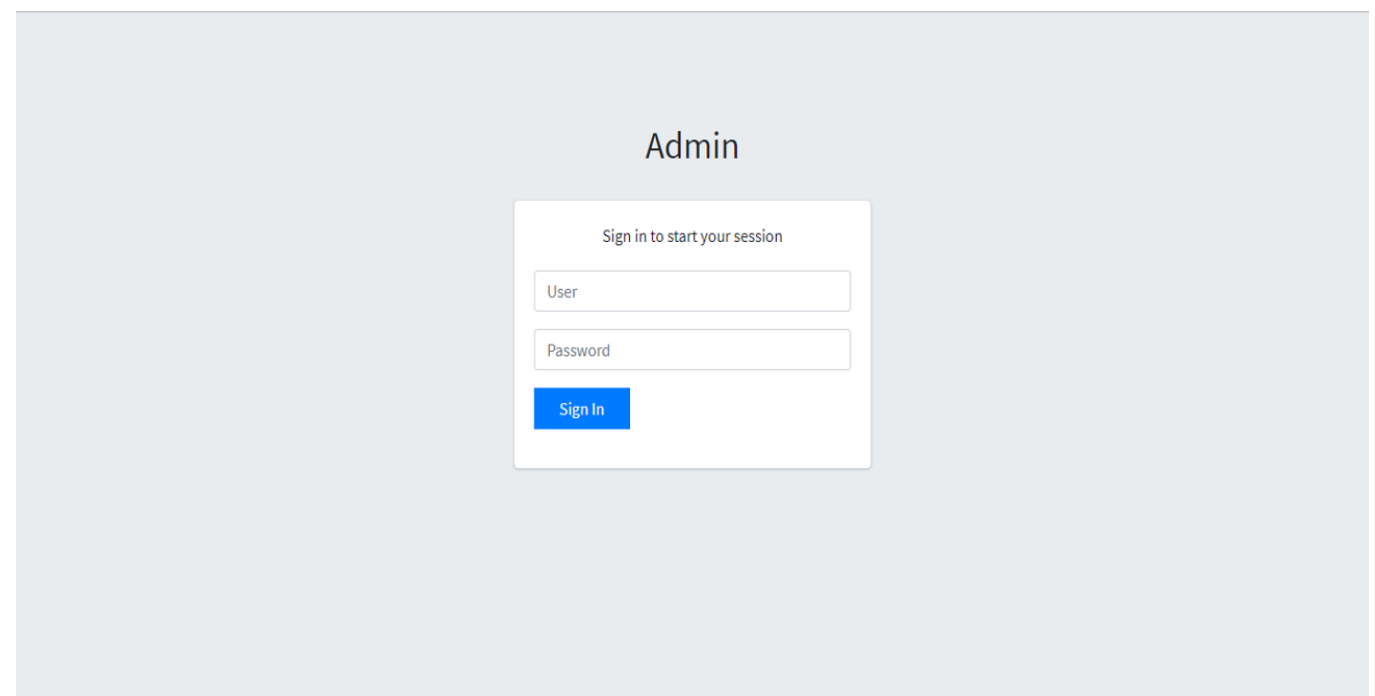

Gambar 7. Login web halaman admin

2. Tampilan Dashboard Web Admin

Dashboard merupakan halaman awal control panel admin yang berfungsi untuk mengelola konten ataupun informasi terdapat juga sub menu dapat dilihat pada Gambar 8 . 


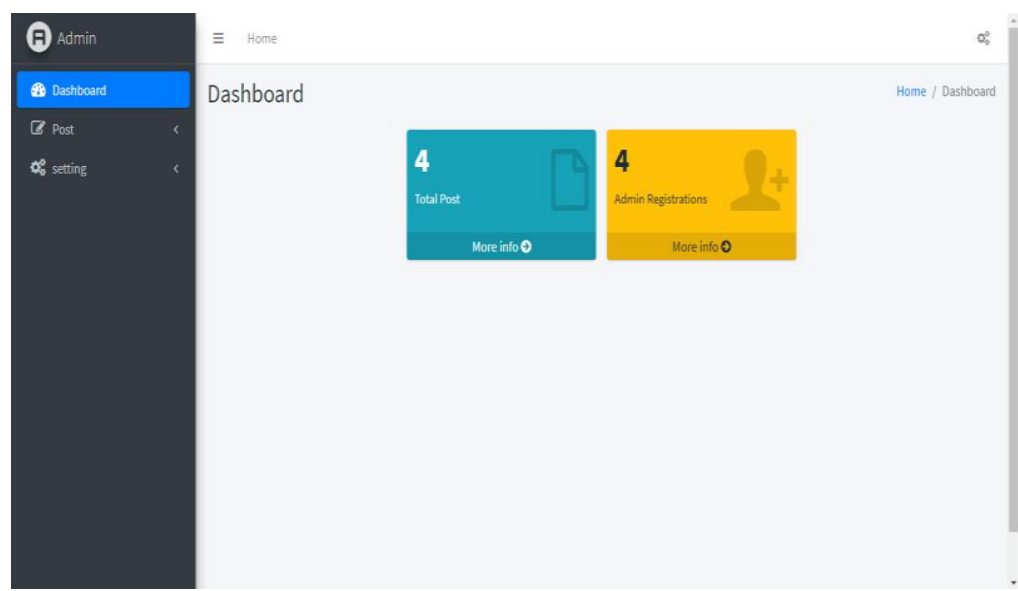

Gambar 8. Tampilan dashboard web admin

\section{Tampilan Daftar Koleksi Batik}

Pada sub menu Lihat terdapat daftar koleksi batik pada menu ini admin dapat melihat koleksi batik yang telah dimasukkan kedalam sistem terdapat juga fitur untuk mengelola data seperti Buat Qr, Lihat, Edit, Delete. Dapat dilihat pada Gambar 9.

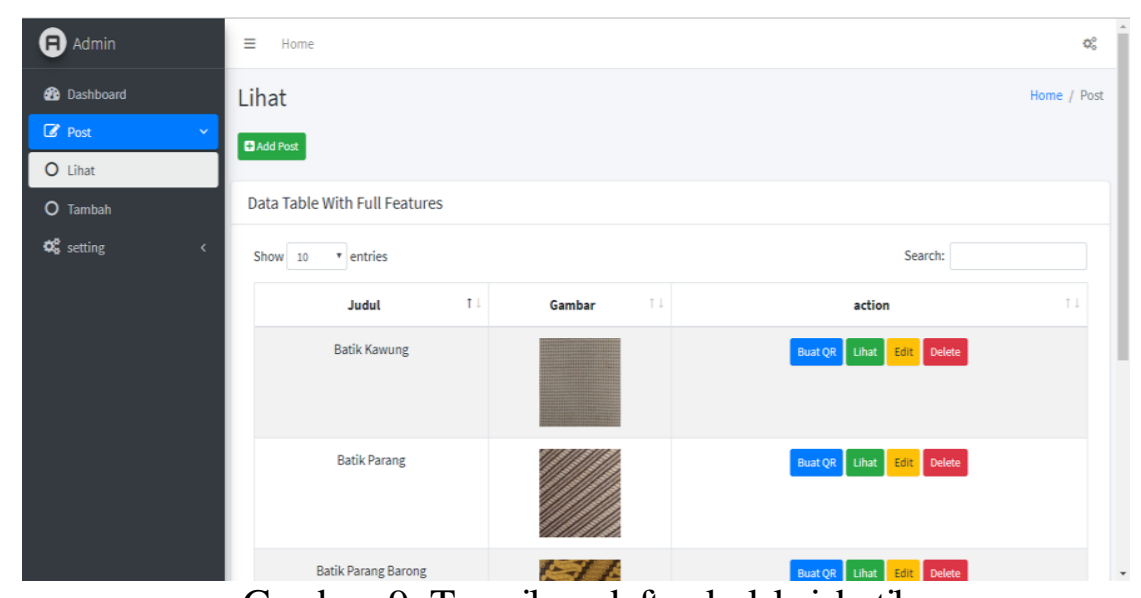

Gambar 9. Tampilan daftar koleksi batik

\section{Tampilan Form Koleksi Batik}

Pada sub menu Tambah atau tombol Add Post terdapat form untuk menambah koleksi batik kedalam sistem. Dapat dilihat pada Gambar 10.

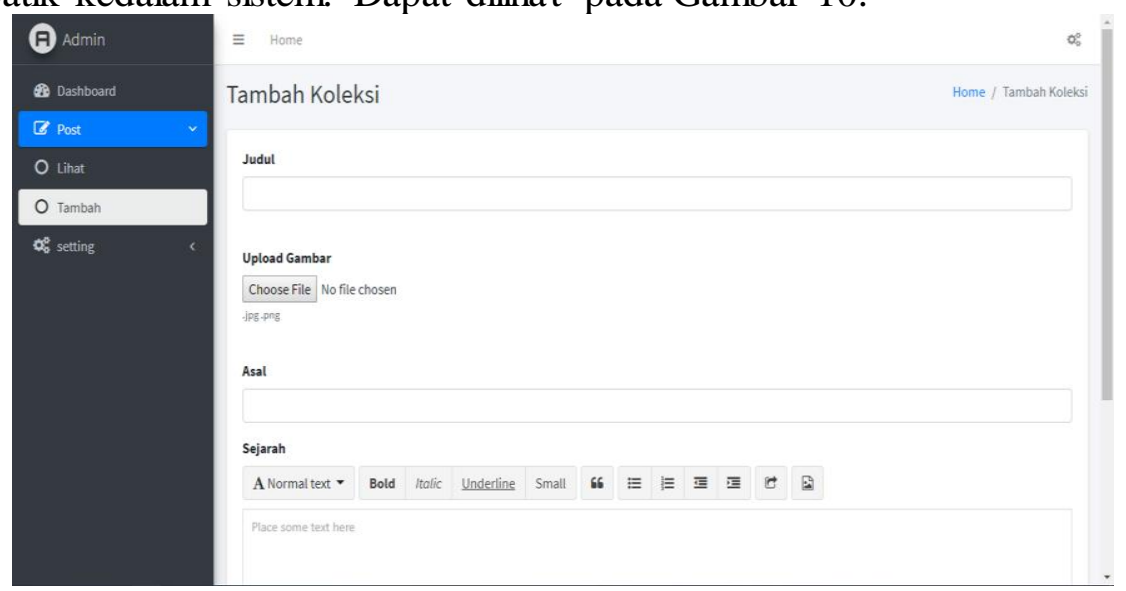

Gambar 10. Tampilan form koleksi batik 


\subsection{Hasil Tampilan Sistem Aplikasi Android User}

Pada hasil Tampilan Aplikasi akan Tampilan aplikasi android ini ditujukan untuk user atau pengunjung yang berfungsi menampilkan informasi koleksi batik.

1. Tampilan Menu Aplikasi Android

Menu ini adalah tampilan awal pada aplikasi android user yang memiliki fungsi diantaranya scan, location, dan about. Dapat dilihat pada Gambar 11.

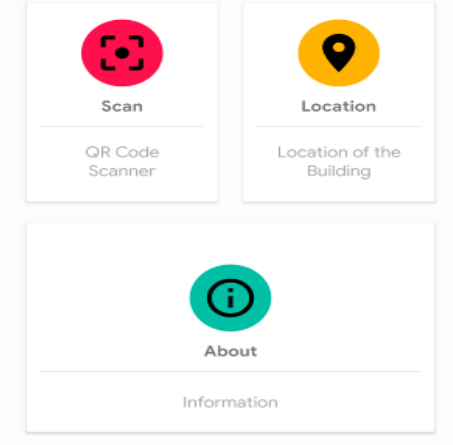

Gambar 11. Tampilan menu aplikasi android

\section{Tampilan Scan Aplikasi Android}

Menu ini berfungi sebagai alat pemindai $Q R$ Code sehingga data yang sudah dimasukkan ke $Q R$ Code dapat diproses dan ditampilkan. Dapat dilihat pada gambar 12

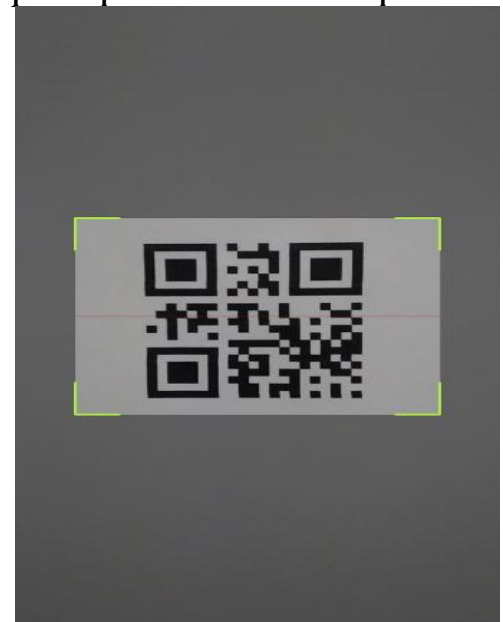

Gambar 12. Tampilan scan aplikasi android

\section{Tampilan Hasil Scan Aplikasi Android}

Pada halaman ini berfungsi sebagai penampil informasi koleksi batik sesuai dengan $Q R$ Code yang telah dipindai sebelumnya disini pengguna memperoleh informasi batik berupa nama batik, asal, dan sejarah yang terkandung dalam batik tersebut. Dapat dilihat pada Gambar 13. 


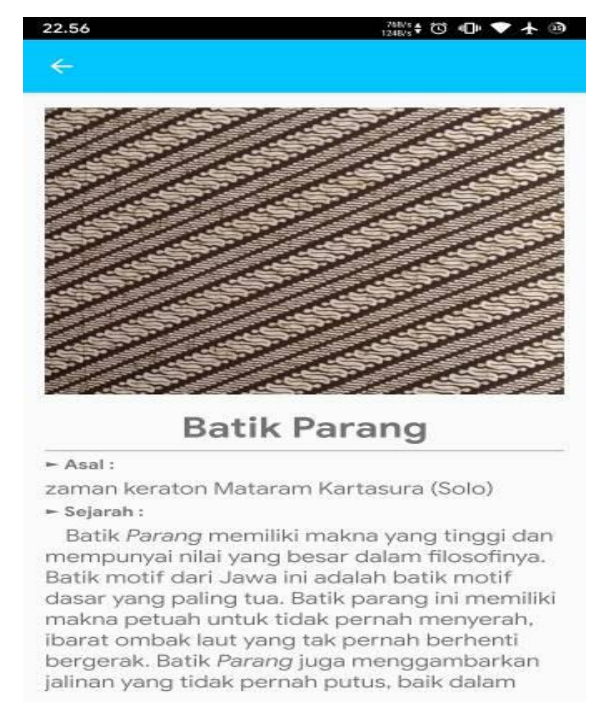

Gambar 13. Tampilan hasil scan aplikasi android

\subsection{Uji $Q R$ Code}

Untuk pengujian $Q R$ Code bertujuan apakah $Q R$ Code dapat dipindai dengan normal. Pengujian meliputi pengujian pencahayaan, jarak, dan coretan dengan simulasi pengujian tersebut diharapkan $Q R$ Code dapat dikelola dengan baik agar data dan fungsi dapat berkeja dengan semestinya.

\section{Pencahayaan}

Tabel 2. Pengujian Pencahayaan pada $Q R$ Code

\begin{tabular}{|c|c|c|}
\hline No & Pengujian & Hasil \\
\hline 1 & Sangat Terang & Berhasil \\
\hline 2 & Terang & Berhasil \\
\hline 3 & Redup & Berhasil \\
\hline 4 & Gelap & Tidak Berhasil \\
\hline 5 & Sangat Gelap & Tidak Berhasil \\
\hline
\end{tabular}

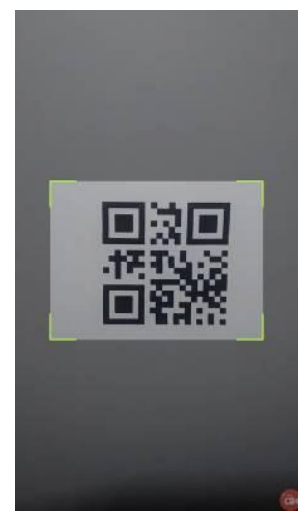

(1)

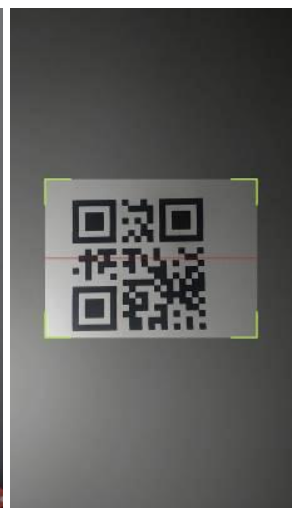

(2)

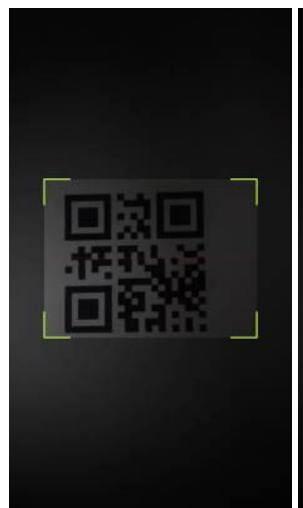

(3)

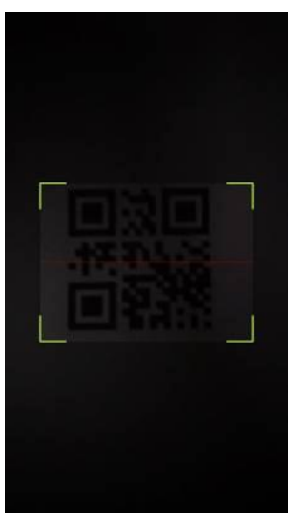

(4)

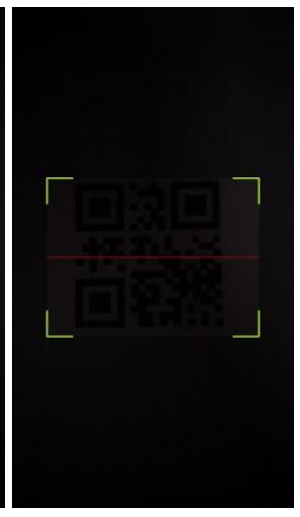

(5)

Gambar 14. Simulasi uji pencahayaan pada $Q R$ Code

Pencahayaan hampir tidak mempengaruhi proses pemindaian dikarenakan tempat tersebut ketika digunakan selalu mendapat cahaya yang cukup berikut adalah hasil simulasi pengujian pencahayaan dapat dilihat pada Tabel 1 dan Gambar 14 adalah merupakan gambar simulasi pengujian. 


\section{Jarak $Q R$ Code}

Tabel 3. Pengujian jarak pada $Q R$ Code

\begin{tabular}{|c|c|c|}
\hline No & Jarak & Hasil \\
\hline 1 & $10 \mathrm{~cm}$ & Tidak Berhasil \\
\hline 2 & $20 \mathrm{~cm}$ & Berhasil \\
\hline 3 & $30 \mathrm{~cm}$ & Berhasil \\
\hline 4 & $40 \mathrm{~cm}$ & Berhasil \\
\hline 5 & $50 \mathrm{~cm}$ & Tidak Berhasil \\
\hline
\end{tabular}

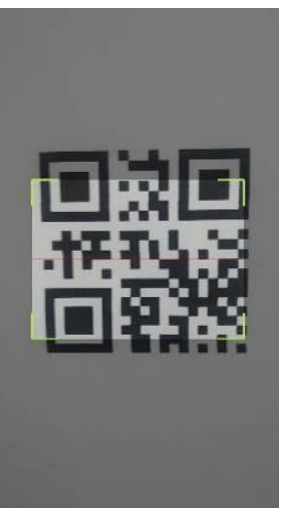

(1)

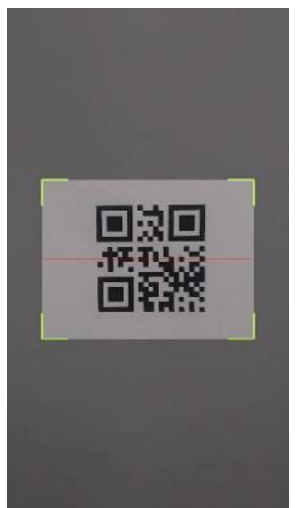

(2)

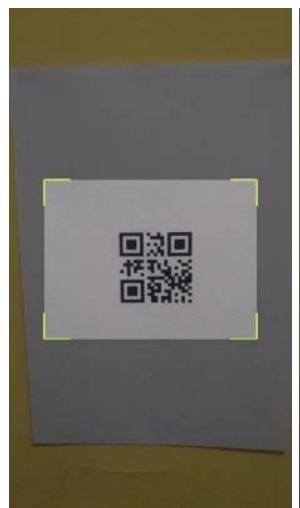

(3)

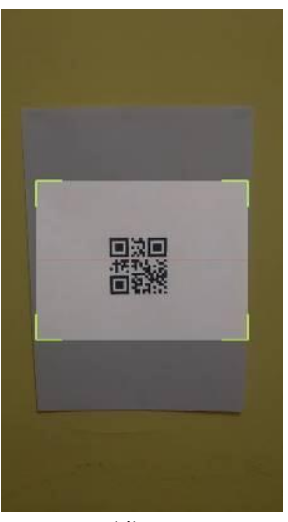

(4)

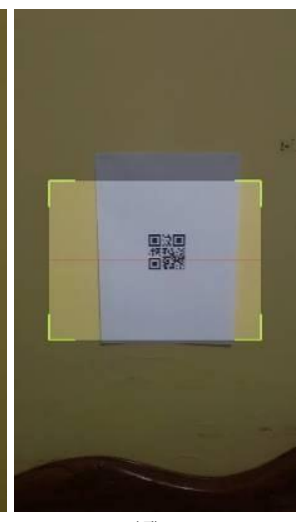

(5)

Gambar 15. Simulasi uji jarak pada $Q R$ Code

Berdasakan pada Tabel 2 pengujian jarak pada $Q R$ Code menghasilkan jarak yang ideal untuk memindai $Q R$ Code sampai ke smartphone merupakan $20 \mathrm{~cm}$ sampai $40 \mathrm{~cm}$. Karena dalam jarak $10 \mathrm{~cm} Q R$ Code tidak masuk kedalam garis hijau pemindai sedangkan dalam jarak $50 \mathrm{~cm}$ proses pemindaian sulit untuk mendapatkan fokus pada QR Code. Simulasi dapat dilihat pada Gambar 15.

3. Coretan pada $Q R$ Code

Tabel 4. Pengujian coretan pada $Q R$ Code

\begin{tabular}{|c|c|c|}
\hline No & Coretan & Hasil \\
\hline 1 & 1 Coretan & Berhasil \\
\hline 2 & 2 Coretan & Berhasil \\
\hline 3 & 3 Coretan & Berhasil \\
\hline 4 & 4 Coretan & Berhasil \\
\hline 5 & 5 Coretan & Tidak Berhasil \\
\hline
\end{tabular}

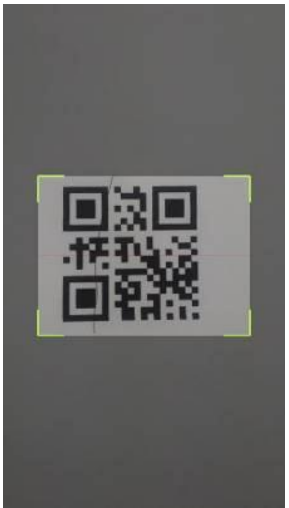

(1)

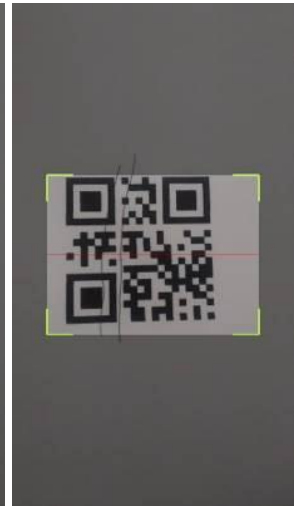

(2)

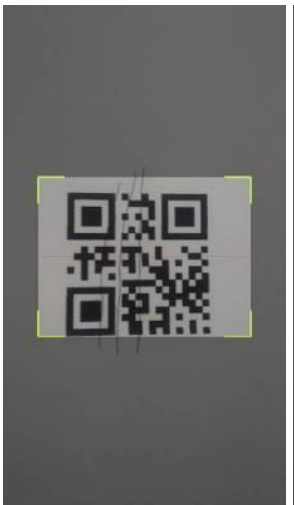

(3)

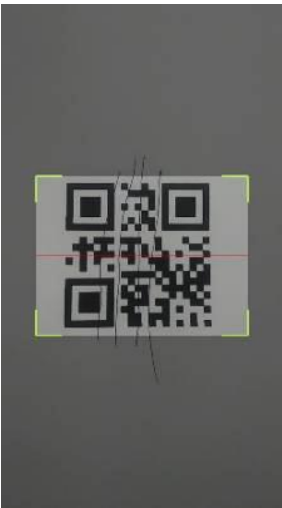

(4)

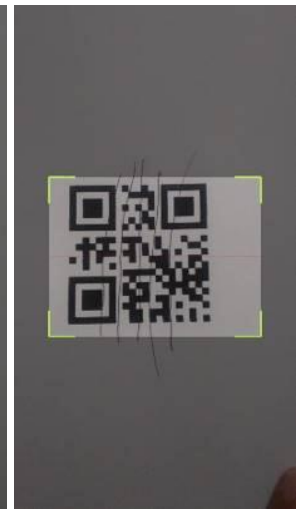

(5)

Gambar 16. Simulasi uji coretan pada $Q R$ Code 
Berdasakan pada Tabel 3 pengujian coretan menggunakan bolpoin pada $Q R$ Code, menunjukkan saat 5 coretan $Q R$ Code tidak bisa dipindai. Karena coretan bolpoin yang terlalu banyak sehingga $Q R$ Code rusak dan pemindai sulit untuk mendapatkan informasi didalam $Q R$ Code. Simulasi dapat dilihat pada Gambar 16.

\subsection{Uji Sistem}

Pengujian sistem bertujuan untuk apakah sistem yang di buat berjalan sesuai dengan yang direncanakan dan semua fitur dapat berfungsi dengan baik.

Tabel 5. Uji coba pada aplikasi Android.

\begin{tabular}{|c|l|l|c|}
\hline No & \multicolumn{1}{|c|}{ Tipe Android } & \multicolumn{1}{|c|}{ Spesifikasi Android } & Hasil Pengujian \\
\hline 1 & Asus Zenfone 3 & Android 9, Ram 4gb/32gb & Berjalan dengan baik \\
\hline 2 & Xiaomi Redmi 3 & Android 6, Ram 2gb/16gb & Berjalan dengan baik \\
\hline 3 & Xiaomi Redmi Note 5 & Android 8, Ram 4gb/64gb & Berjalan dengan baik \\
\hline 4 & Realme 2 Pro & Android 8, Ram 6gb/64gb & Berjalan dengan baik \\
\hline 5 & Asus Zenfone Max Pro M1 & Android 8, Ram 3gb/32gb & Berjalan dengan baik \\
\hline
\end{tabular}

Berdasarkan hasil pada Tabel 4, dilakukan pengujian beberapa tipe android dengan berbagai spesifikasi dan berbagai OS Aplikasi yang digunakan pengguna dapat berjalan dengan baik.

\section{KESIMPULAN DAN SARAN}

\subsection{Kesimpulan}

Sistem Penampil Informasi Koleksi Batik Di Gedung Siti Walidah berhasil lolos dengan pengujian black-box dan berhasil dibuat dan berfungsi dengan baik seperti yang diharapkan. Kesimpulan yang bisa diambil dari penelitian adalah:

1. Hasil pengujian $Q R$ Code menunjukkan

- Kondisi cahaya hamper tidak mempengaruhi proses pemindaian selain itu ditempat yang digunakan memiliki kondisi cahaya yang baik ketika ruangan sedang digunakan

- Jarak pemindaian yang dilakukan dengan smartphone yang sudah diinstal aplikasi bisa dilakukan dengan jarak optimal $20 \mathrm{~cm}$ sampai $40 \mathrm{~cm}$

2. Pengujian terhadap aplikasi android yang dibuat untuk pengguna berhasil lolos dengan dilakukan pengetesan diberbagai smartphone dengan spesifikasi yang berbeda-beda dan memiliki beberapa macam OS yang berbeda

\subsection{Saran}

1. Menambah fitur yang sekiranya berguna bagi pengguna

2. Menyempurnakan tampilan dan mengoptimasi fungsi aplikasi supaya pada penggunaan lebih bisa lebih baik lagi

\section{DAFTAR PUSTAKA}

Adrianto, D., Yesmaya, V., Agung, A., Ivander, D. T., Elysia, E., \& Natalie, N. (2015). $Q R$ Code Reader pada Smartphone Android untuk Aplikasi Layanan Restoran. ComTech: Computer, Mathematics and Engineering Applications, 6(2), 266.

https://doi.org/10.21512/comtech.v6i2.2271

Nugroho, B. A., \& Efendi, F. S. (2018). Pengembangan Aplikasi Android Berbasis 
Teknologi Cloud Computing Dan $Q R$ Code Untuk Pendataan Bus Dan Penumpang Di Terminal Tipe-A Tamanan Kota Kediri, 1017-1026.

Pal, S. K., \& Jha, K. K. (2017). Personal Marketing Framework based on QR Code. Scholedge International Journal of Multidisciplinary \& Allied Studies ISSN 2394336X, 4(8), 65. https://doi.org/10.19085/journal.sijmas040801

Pandya, K. H., \& Galiyawala, H. J. (2014). International Journal of Emerging Technology and Advanced Engineering A Survey on $Q R$ Codes: in context of Research and Application. International Journal of Emerging Technology and Advanced Engineering, 4(3), 258. Retrieved from www.ijetae.com

Raj, S. S., Subramanian, S. S., \& Rupasudha, P. (2017). Online toll payment system using android application, 04(02), 48-50.

Shamal, S., Monika, K., \& Neha, N. (2014). International Journal of Emerging Technology and Advanced Engineering Secure Authentication for Online Banking Using $Q R$ Code. Www.Ijetae.Com, 4(3), 778-781. Retrieved from www.ijetae.com

Ugwu, C., \& Mesigo, T. (2015). A Novel Mobile Wallet Based on Android OS and Quick Response Code Technology, 3(1). 